\title{
Indicators of the Anthropocene: is there a case for conservation?
}

\author{
Hannah Jordan ${ }^{1}$; Colin Prosser ${ }^{2}$ \\ ${ }^{1}$ British Geological Survey, Keyworth, Nottingham, NG12 5GG, UK, hann@bgs.ac.uk; \\ ${ }^{2}$ Natural England, Unex House, Bourges Boulevard, Peterborough, PE11NG, UK.
}

\section{Summary}

The Earth's atmosphere, biosphere and lithosphere are increasingly being modified by human activity. Given this anthropogenic influence on the natural environment, the case for recognising an Anthropocene Epoch has recently been made and there is ongoing debate as to whether, and how, to formally characterise and define such an epoch. As a contribution to this debate, this article explores whether or not the landscapes, deposits, landforms and key marker horizons that may be used to characterise and define an Anthropocene Epoch could, and should, be identified and conserved in the same manner as other parts of the geological succession. Anthropogenic features pose a conservation challenge, however, as they often cross-cut existing conservation frameworks which tend to focus on the natural, historic or cultural environment. Developing a coherent approach to the conservation of the indicators of an Anthropocene Epoch would, therefore, require an integrated system of describing, auditing and designating features for conservation. A major benefit of such an approach would be the opportunities for interdisciplinary collaboration between the wide range of researchers interested or involved in studying and conserving the record of anthropogenic activity.

\section{Main text}

Humans are leaving an ever increasing imprint on the Earth's atmosphere, biosphere and lithosphere. Indeed, human activity has been, and continues to be, responsible for changes in climate, sedimentation rates, ocean and atmospheric chemistry and plant and animal distributions, amongst other factors. Whilst the effects of some of these changes are more subtle than others, and in many cases will be diachronous, the rate at with which they are occurring is unprecedented. As the global population continues to increase, the impact of humans on the Earth will intensify further. In addition, technological innovation is allowing the zone of human interaction to expand into previously inhospitable terrestrial regions, beyond the terrestrial near-surface to greater depths and into offshore areas. This means that the ratio of anthropogenic to natural features can be expected to increase as the Earth becomes increasingly modified by human activity.

In light of this expanding anthropogenic footprint, proposals are being made to recognise a geological epoch defined by the action of humans: the Anthropocene. Whilst consensus is yet to be reached as to how best to define the exact start and character of this proposed epoch, a number of indicators of human activity of geological and archaeological significance exist which could be used to characterise the Anthropocene. These include: anthropogenically modified landscapes; anthropogenic landforms and deposits and; key marker horizons such as altered atmospheric greenhouse gas concentrations and human-induced animal extinctions (Figure 1). 

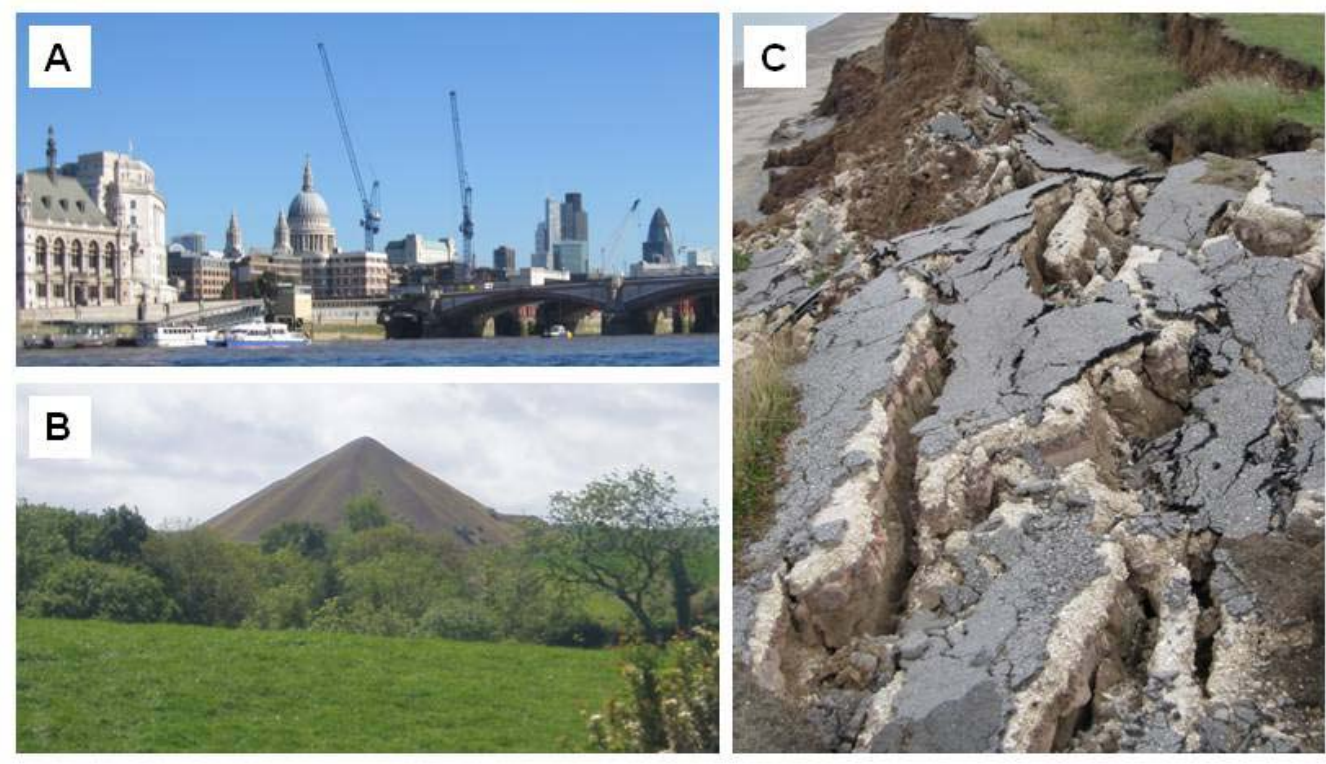

Figure 1. Examples of anthropogenic indicators: A) London cityscape- an anthropogenically-modified landscape; B) mining spoil heap in North Yorkshire forming a prominent anthropogenic landform and; C) building rubble and tarmac- an anthropogenic deposit on the east coast of Yorkshire. Photographs (C) BGS/NERC.

Many key features that are used to characterise stratotypes and type localities in other parts of our geological and archaeological record are being audited, recorded and conserved in order to facilitate understanding of the period of time in question. At present, approaches to the identification and conservation of the Anthropocene indicators are piecemeal and, in lying across the disciplines of geology, soil science, geomorphology, history and archaeology, they cross-cut existing conservation frameworks. Additionally, anthropogenic activities have the potential to provide positive and/or negative environmental and societal impacts and these must also be considered when assessing the case for, or against, the conservation of anthropogenic features. Through outlining some of the characteristics and potential indicators of the proposed Anthropocene Epoch, this article aims to stimulate debate as to whether or not auditing and conserving anthropogenic features is desirable or practical.

\section{The Anthropocene}

Many anthropogenically-driven processes, including sedimentation and erosion, habitat modification and animal extinction, now out-pace their natural counterparts. For example, on a global scale current anthropogenic sediment movement in the terrestrial realm has been estimated to exceed that from natural processes by an order of magnitude, and many areas now display artificial deposits and landforms at the ground surface (Figure 2). Presently, 'the Anthropocene' is only used informally although it has been widely adopted in both scientific literature and the media. If formalised, it would represent the phase of geological time in which we live today. 

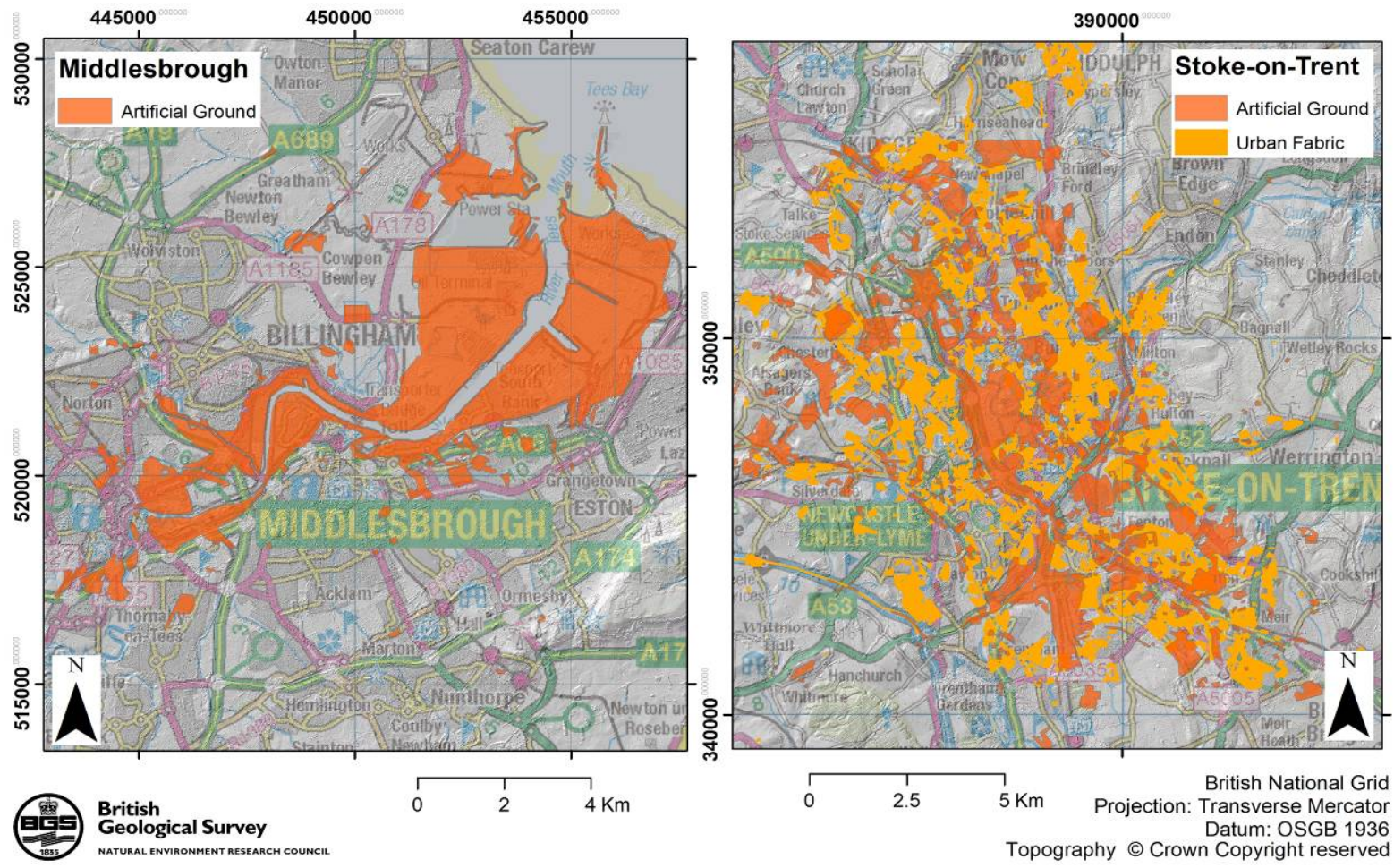

Figure 2. Anthropogenic deposit coverage in two selected UK areas. Artificial ground for Middlesbrough and Stoke-on-Trent derived from BGS DiGMapGB-50. Stoke-on-Trent urban fabric represents buildings and infrastructure derived from the European Environment Agency Urban Atlas.

Typically units of geological time are defined by reference to a particular point within a geological sequence (Global Boundary Stratigraphic Section and Point, GSSP) or a designated time boundary (Global Standard Stratigraphical Age, GSSA). Indicators of anthropogenic activity such as anthropogenically modified landscapes, anthropogenic deposits and landforms and key anthropogenic markers each have a potential stratigraphical impact thorough generating new lithologies and landforms, impacting upon the fossil record, or providing key chemical signatures within a stratigraphy. These indicators can be used to help define the Anthropocene's GSSP or GSSA or delineate subdivisions within the proposed epoch if appropriate and useful to do so. The exact time frame that the Anthropocene would represent is still under debate and a range of possible 'start dates', corresponding to a variety of indicators, have been proposed. These include dates related to the onset of the Industrial Revolution (AD 1750-1800); the advent of anthropogenic soils (2,000 Before Present, BP); early agriculture (8,000-5,000 BP); the appearance of domesticated plants and animals $(11,000-9,000 \mathrm{BP})$ and the extinction of mammoths ( 13,800BP).

Potential indicators of the Anthropocene exist at a range of spatial scales and include anthropogenically modified landscapes at the land systems level, anthropogenic deposits and landforms as components of landscapes and key marker horizons. These indicators may be found in several locations throughout the world, at regional scales or locally. Some of these features will be purely artificial, being composed of man-made materials or chemicals that are not naturally occurring whilst others may represent a combination of natural and artificial components. There may also be a category formed of materials that are naturally occurring but that would not be found in a particular location without the action of humans; for example, where humans have altered coastal sediment dynamics to such an extent that a 
beach may be found in a location where the natural sediment supply is so low or wave action so erosive that one would not naturally exist.

Anthropogenically modified landscapes typically reflect the surface expression of the underlying geology and the natural and artificial components that have transformed it. Industrial or urbanised landscapes characterised by, for example, buildings, spoil heaps and made ground are perhaps the most obvious forms of anthropogenic landscapes. Other less urban anthropogenically modified landscapes include landscaped gardens such as the Capability Brown landscapes of Blenheim Palace, Oxfordshire and Warwick Castle, Warwickshire. Most, if not all, rural landscapes are also anthropogenically modified, having been subject to changes in vegetation, drainage patterns and topography. There is currently no established, coherent method for mapping or recording anthropogenically modified landscapes specifically for their potential role in characterising the proposed Anthropocene Epoch.

Anthropogenic deposits and landforms may comprise 'natural' deposits that have been reworked by humans, for example an engineering embankment comprising reworked deposits of Mercia Mudstone, and/or 'artificial' material such as household rubbish and building rubble. As well as contributing to the subsurface stratigraphy of an area these deposits form depositional and erosive landforms. For example, in an area of Great Yarmouth, UK 14.77\% of what would traditionally be regarded as Holocene deposits is, in fact, derived from anthropogenic sources. Even in this area of relatively subdued topography, these deposits raise the land surface locally by as much as $5.08 \mathrm{~m}$. Buildings and infrastructure at the ground surface could also be considered as anthropogenic deposits and landforms. In this case, these features are regarded as having a geomorphological expression, with humans acting as geomorphological agents through a form of bioturbation. It has been estimated that approximately $4 \%$ of mainland Britain is covered by artificial deposits, although with the inclusion of buildings and infrastructure at the ground surface this figure is likely to be much greater.

Anthropogenic deposits and landforms in the UK have been classified on geological maps produced by the British Geological Survey (BGS) as Made Ground, Worked Ground, Disturbed Ground, Landscaped Ground or Infilled Ground. A more recent enhancement of this morpho-stratigraphic scheme allows these classes to be subdivided into "types" and "units" (Figure 3). Archaeologically important artificial ground is currently not explicitly provided for; instead sub-division based on the English Heritage Archive (previously the National Monuments Record) classification is suggested as part of the BGS scheme. Buildings and infrastructure at the ground surface are also currently not included. Selected examples of these may be catalogued under heritage guidelines such as Listed Buildings or Scheduled Monuments. 


\section{$\begin{array}{lll}\text { CLASS } & \text { TYPE } & \text { UNIT }\end{array}$}

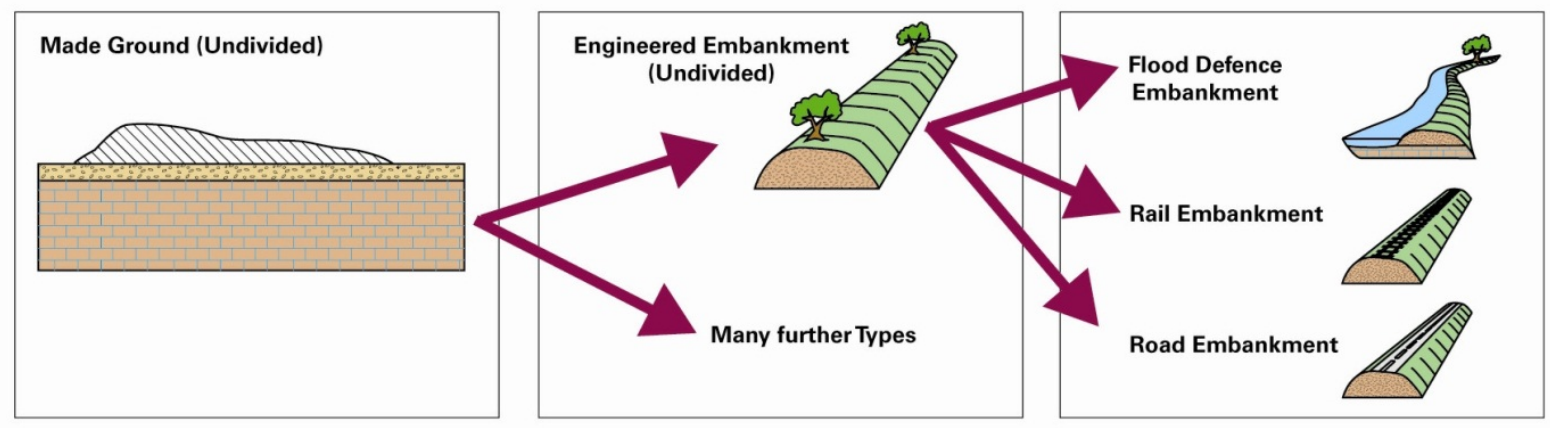

Figure 3. Extract from the BGS Enhanced Artificial Ground Classification.

Key anthropogenic markers can be used to sub-divide the Anthropocene Epoch based on major events in human history. For example, it has been suggested that the Anthropocene can be categorised into 3 stages: the Industrial Era (c.1800-1945), the Great Acceleration (1945-c.2015) and the Stewardship Phase (c.2015-?). Each of these phases corresponds to a change in the type or rate/intensity of human activity and can be identified from increased atmospheric $\mathrm{CO}^{2}$ concentration, increased levels of urbanisation, and increased levels of carbon sequestration, respectively.

The full range of potential key markers of the Anthropocene remains a subject for discussion and at present there is no coherent method for auditing them. As well as geological, biological and archaeological markers, economic and cultural factors such as Gross Domestic Product and levels of international tourism may also help to define the Anthropocene. Whilst these indicators may impact less directly on the stratigraphic record and, therefore, have less relevance in defining a GSSP for the Anthropocene, they can aid in identifying a chronology and GSSA. As such, practitioners from the economic, political and social spheres should be included in discussions about Anthropocene markers if an exhaustive list is to be developed.

Anthropogenic landscapes and deposits and landforms will typically preferentially develop in terrestrial rather than marine zones, given the differing intensities of human activity in these areas. A marine expression for the Anthropocene is not unexpected, however, as any deposits or landforms developed in or transported to these regions may have a higher preservation potential than their terrestrial equivalents. In addition, some key markers such as sequestered $\mathrm{CO}_{2}$ may preferentially develop in marine zones. As the proposed Anthropocene Epoch would include the present and future, as well as the anthropogenic past, its characteristics and indicators cannot yet be fully developed. As such, any methods for identifying and auditing these indicators must be flexible enough to take account of changes in anthropogenic features as they evolve through time.

\section{Conservation and the Anthropocene}

Most countries now actively seek to identify, conserve and manage the highlights of their natural, historic and cultural heritage and many already have legislation, policies and frameworks in place through which to achieve this. In the UK, for example, the designation of National Parks and Areas of Outstanding Natural Beauty (AONBs) and the inscription of World Heritage Sites (WHS) provide a means of conserving and enhancing the finest landscapes. Sites of Special Scientific Interest (SSSIs) and Local Sites allow for the 
conservation of nationally and locally important geological, geomorphological and wildlife features and Scheduled Monument status provides protection for features of national historic or prehistoric importance.

Whilst it is undoubtedly important to science and society that the best of our natural and cultural heritage is being recognised and conserved, how relevant is what is already happening in terms of conservation, to the study of anthropogenic landscapes, deposits and landforms or key markers, or to the establishment of an Anthropocene Epoch? Attempting to answer this question generates further questions, such as: are there anthropogenic landscapes, deposits and landforms or markers that are important enough and threatened enough to be worthy of conservation?; if so, what are they and where are they?; if there are such features are they already being conserved through existing conservation legislation, policies or frameworks, and; if not, how and by whom should such landscapes, deposits, landforms or markers be conserved?

Recognising and potentially conserving the key features which may define and characterise the Anthropocene is essential if it is to be a robust and scientifically sustainable epoch. In addition to characterising the proposed Anthropocene Epoch, anthropogenic landscapes, deposits, landforms and key markers have the potential to positively and negatively impact upon social and environmental systems (Figure 4). For example, these features may be of environmental, historic or cultural importance, potential mineral resources, educational sites or ecological niches. Conversely, they could represent a geological hazard, they may be contaminated, may lower the aesthetic value of existing natural features or damage ecosystems and destabilise geomorphological processes. These varied impacts need to be taken into account in deciding the suitability of Anthropocene indicators for conservation.
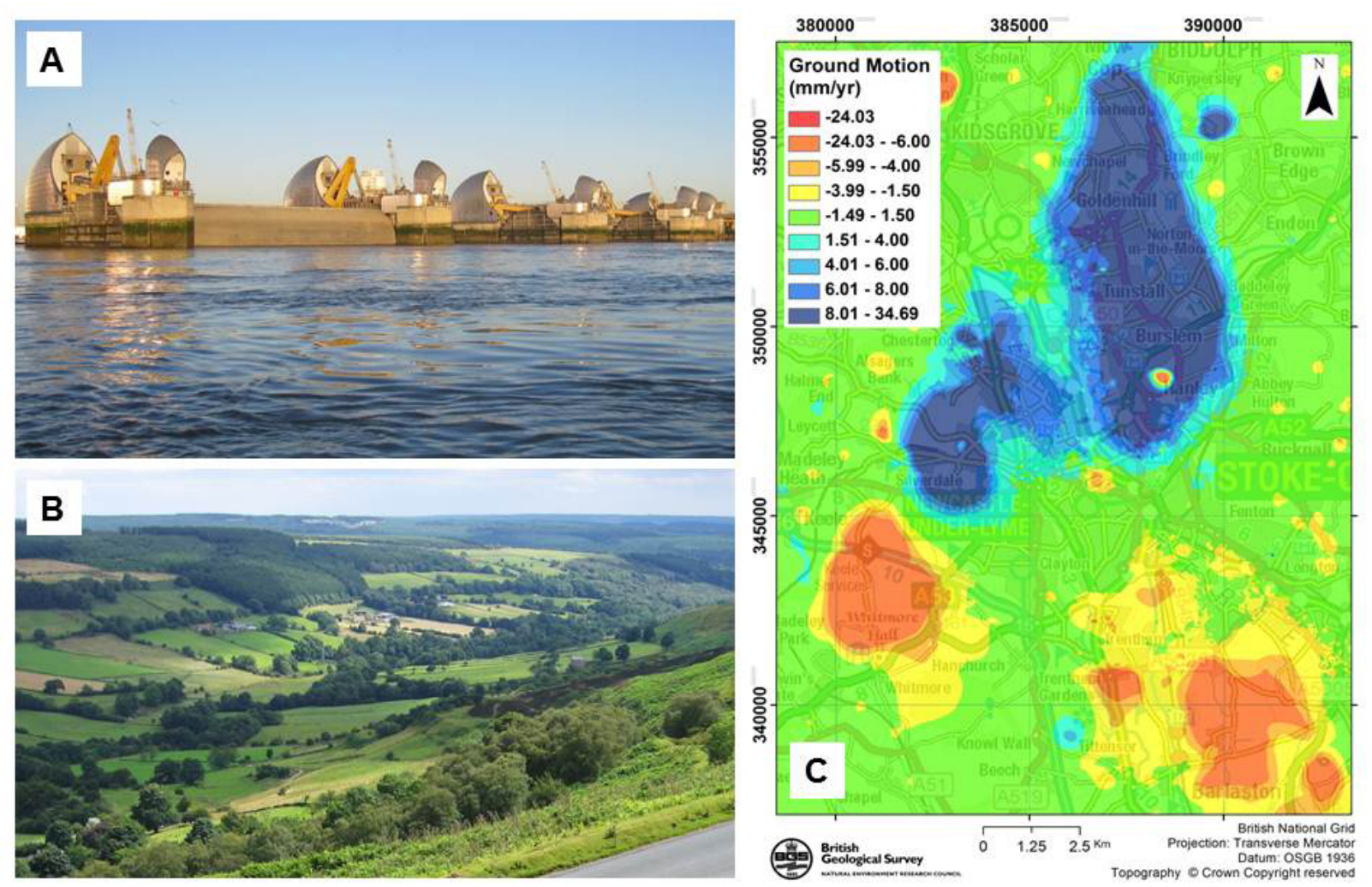

Figure 4. Selected positive and negative effects of anthropogenic indicators including: A) flood protection afforded by the Thames Barrier; B) the agricultural landscape of the North York Moors National Park- an 
important natural, cultural and recreational resource and C) areas of anthropogenically-induced ground motion hazard in Stoke-on-Trent identified from Persistent Scatterer Interferometry (PSI). Photographs (C) BGS/NERC. PSI data reproduced with permission from Tele-Rilevamento Europa.

Assuming that there are anthropogenic landscapes, deposits and landforms or markers deemed worthy of conservation, it will be important to establish the relationship between what would need to be conserved and what is already being conserved through existing means. It can be argued that most, if not all landscapes, are already anthropogenically modified. This may be through agricultural use, land management, mineral working or the construction of buildings and infrastructure. The value of these landscapes is often recognised already. In many cases they are conserved and enhanced through designation as WHS, Global Geoparks, National Parks, AONBs, Registered Parks and Gardens or through commitments made to implement frameworks such as the European Landscape Convention. Examples of anthropogenically modified landscapes which are already subject to conservation and management within the UK include the Roman wall and forts in the Hadrian's Wall WHS and Northumberland National Park, northern England; the mining landscapes of the Cornish Mining World Heritage WHS, south west England and; agricultural landscapes such as those of the Gower AONB in South Wales and the South Downs National Park, southern England.

Anthropogenic deposits and landforms are also already often subject to conservation and management. These tend to be of scientific, historic or prehistoric importance, with many being archaeological sites. Conserved sites of this type might include quarries or mine tips managed as SSSIs on account of their geology, ecological significance or mineralogy, but also of anthropogenic interest, and Scheduled Monuments protected for their record of prehistoric or historic activity (e.g. earthworks, sites of early mineral extraction or important settlements) (Figure 5). There are, of course, many anthropogenic features, such as recent made ground, that are not currently deemed to have any natural or cultural value, although they may be viewed differently in time, and as such are not conserved in any way. In contrast, certain anthropogenic features may be regarded as having significant negative environmental impacts; for example modern flood defence bunds, which are seen by many as being damaging through their disruption of natural geomorphological and ecological processes.

Anthropogenic marker horizons are perhaps the features currently least recognised in existing approaches to conservation, although some may be included incidentally in existing conserved sites. Markers may represent the first or last appearance or peak of key anthropogenic activities such intense agricultural activity, large-scale coal production or atomic testing and have the potential to play a critical role in defining and subdividing an Anthropocene Epoch. The identification and conservation of such markers, providing they do not cause adverse environmental impact would be extremely important in sustaining a credible Anthropocene Epoch, in the same way that the key stratigraphical horizons are already conserved within the global geological succession. It is this area in which most new thought and action would be required should an approach to conserving an Anthropocene Epoch be established. 


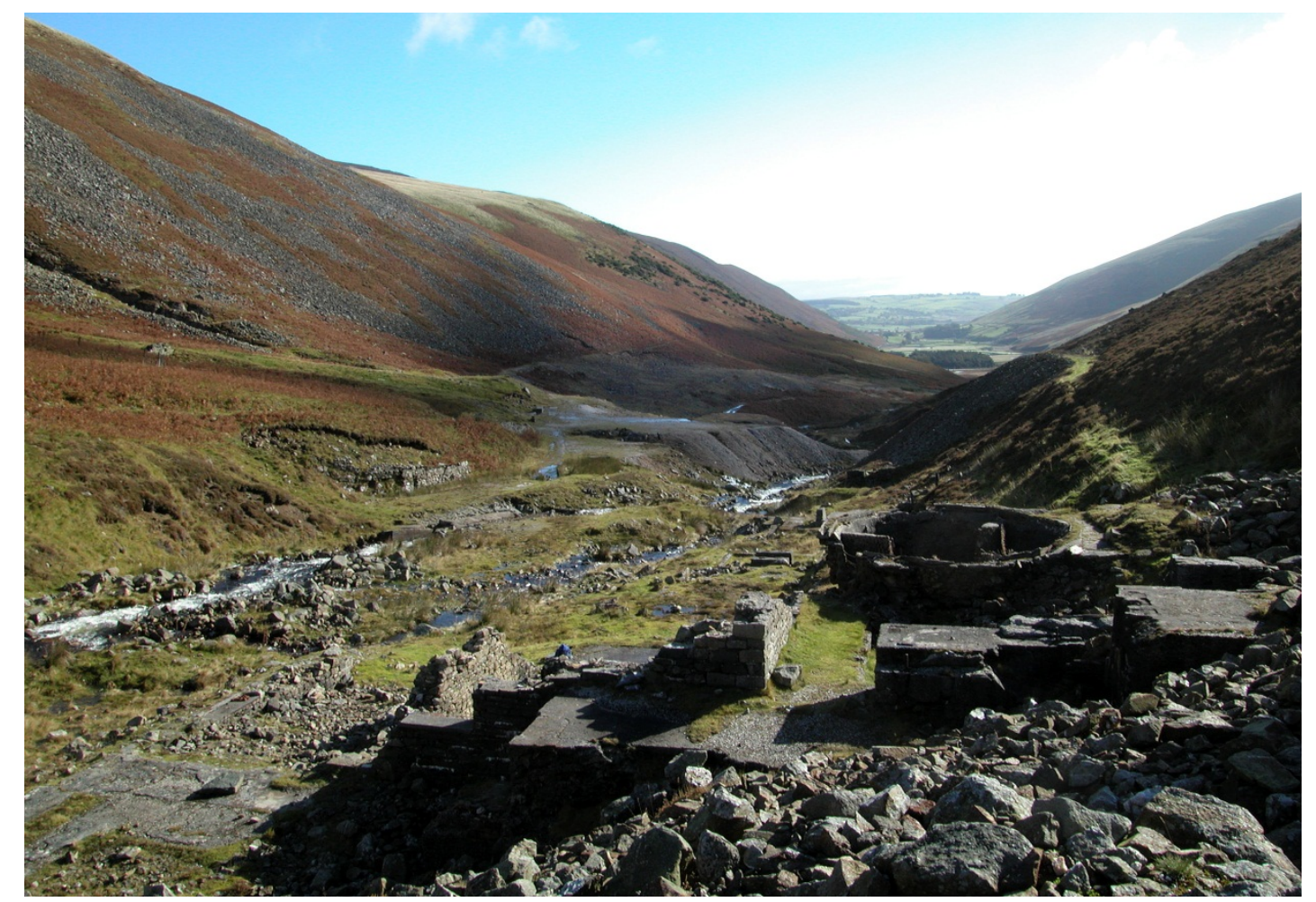

Figure 5. Many anthropogenic landscapes, deposits and landforms are already conserved through existing conservation frameworks. Carrock Mine, Cumbria, England, for example, is already designated for its nationally important mineralogy as part of the Skiddaw Group SSSI and as a Scheduled Monument for providing an important historic record of tungsten, lead, copper, and arsenic mining and the remains of an early 20th century tungsten mill. Photograph by Hannah Townley, Natural England.

\section{Conservation in practice}

Despite the fact that some anthropogenic features are already, albeit often incidentally, conserved through existing conservation frameworks, a systematic approach to anthropogenic conservation will inevitably depend on whether or not an Anthropocene Epoch is established and whether it is useful to do so. With the inter-disciplinary nature of the Anthropocene debate and with different organisations already involved in aspects of anthropogenic conservation, integrated and inclusive partnerships between geologists, historic environment specialists, archaeologists, conservationists and others and a coherent and consistent approach will be essential. A number of themes will need to be considered in order to establish an effective delivery mechanism for the conservation of key features of the Anthropocene. These include: determining which landscapes, deposits and landforms and markers should be conserved; how these could be characterised and audited in a consistent manner; which of these features would be 'conserved' with a degree of managed change being acceptable and; which should be 'preserved' with as little change as possible.

Decisions would also need be made as to how much of the existing conservation activity could be included within the scope of anthropogenic conservation and where brand new approaches would be needed. Importantly, choices would have to be made around which legislation, policies, frameworks and organisations would be used to conserve which features, and how to conserve key features where no appropriate means currently exists. Finally, the conservation approach would need to be flexible enough to accommodate new anthropogenic landscapes, deposits, landforms and markers that may emerge in the future. 


\section{Conclusions}

Anthropogenic landscapes, deposits, landforms and markers are becoming increasingly dominant features of the Earth's lithosphere, atmosphere and biosphere. Should an Anthropocene Epoch be established to recognise this phase of human impact on the environment, it would be logical to conserve and manage the features that are used to define it: as is done for other divisions of geological time. Whilst some anthropogenic features are already conserved under existing conservation practice, a systematic, joined-up approach would be required in order to adequately conserve representative and valued indicators of the Anthropocene. The interdisciplinary partnership and collaboration needed to achieve this could provide major benefits in terms of developing integrated research and conservation policy and practice. Whether or not the Anthropocene Epoch is formally recognised, the increasing presence of anthropogenic landscapes, deposits, landforms and markers on Earth cannot be overlooked in terms of environmental management and conservation practice.

\section{Acknowledgements}

Anthony Cooper, Simon Price and Vanessa Banks (all of BGS), Eleanor Brown, Victoria Hunns, Jonathan Larwood and Barbara Silva (all of Natural England) and Murray Gray (Queen Mary, University of London) are thanked for invaluable comments and discussion throughout the preparation of the article. H. Jordan publishes with the permission of the Executive Director of the British Geological Survey, Natural Environment Research Council (NERC). The National Grid and other Ordnance Survey data (C) Crown Copyright and database rights 2012. Ordnance Survey license number 100021290. NEXTMap Britain elevation data from Intermap Technologies.

\section{Suggestions for further Reading}

Certini, G., Scalenghe, R. 2011. Anthropogenic soils are the golden spikes for the Anthropocene. The Holocene, v.21, pp.1269-1274.

Ford, J., Kessler, H., Cooper, A.H., Price, S.J, Humpage, A.J. 2010. An Enhanced Classification for Artificial Ground. British Geological Survey Open Report OR/10/036. 32pp.

Gale, S., Hoare, P. 2012. The stratigraphic status of the Anthropocene. The Holocene, v.22, pp.1491-1494

Jordan, H., Cigna, F., Bateson, L. In Press. Stoke on Trent Geohazard Description. PanGeo EU FP7 Project. http://www.pangeoproject.eu/

Jordan, H., Hamilton, K., Lawley, R. (In Preparation) Anthropogenic contribution to the geological record: A case study from Great Yarmouth, Norfolk, UK.

Last, J., Bridgland, D., Brown, E., Harding, P. In press. Quaternary geoconservation and Palaeolithic heritage protection in the $21^{\text {st }}$ Century: developing a collaborative approach. Proceedings of the Geologists’ Association, 124, pp. 625-637. 
Price, S.J., Ford, J.R., Cooper, A.H. \& Neal, C. 2011. Humans as major geological and geomorphological agents in the Anthropocene: the significance of artificial ground in Great Britain. Philosophical Transactions of the Royal Society A, v.369, pp.1056-1084.

Prosser, C.D. 2013. Our rich and varied geoconservation portfolio: the foundation for the future. Proceedings of the Geologists’ Association, v.124, pp.568-580.

Prosser, C.D., Bridgland, D.R., Brown, E.J. \& Larwood, J.G. 2011. Geoconservation for science and society: challenges and opportunities. Proceedings of the Geologist's Association, v.122, pp.337-342.

Smith, B. D., Zeder, M. A. In Press. The Onset of the Anthropocene. Anthropocene.

Steffen, W., Crutzen, P. J., McNeill, J. R. 2007. The Anthropocene: Are Humans Now Overwhelming the Great Forces of Nature? Ambio, v.36(8), pp.614-621.

Steffen, W., et al., 2011. The Anthropocene: From Global Change to Planetary Stewardship. Ambio, v.40(7), pp.739-761.

Thomas, M.F. 2012. A Geomorphological Approach to Geodiversity- Its Application to Geoconservation and Geotourism. Quaestiones Geographicae, v.31, no.1, pp.81-89.

Zalasiewicz, J., Williams, M., Steffen, W. \& Crutzen, P. 2010. The new world of the Anthropocene. Environment, Science and Technology, v.44, pp.2228-2231.

Zalasiewicz, J., Williams, M., Haywood, A. \& Ellis, M. 2011. Introduction. The Anthropocene- A new epoch of geological time? Philosophical Transactions of the Royal Society A, v.369, pp.833-834.

Zalasiewicz, J. et al., 2011. Stratigraphy of the Anthropocene. Philosophical Transactions of the Royal Society A, v.369, pp.1036-55.

http://www.eea.europa.eu/data-and-maps/data/urban-atlas 